\title{
Dopaminergic Modulation of Mitral Cells and Odor Responses in the Zebrafish Olfactory Bulb
}

\author{
Sebastian T. Bundschuh, ${ }^{1,2}$ Peixin Zhu, ${ }^{1}$ Yan-Ping Zhang Schärer, ${ }^{1}$ and Rainer W. Friedrich ${ }^{1,2}$ \\ ${ }^{1}$ Friedrich Miescher Institute for Biomedical Research, 4058 Basel, Switzerland, and ${ }^{2}$ University of Basel, 4003 Basel, Switzerland
}

In the olfactory bulb, the modulatory neurotransmitter dopamine (DA) is coexpressed with GABA by local interneurons, but its role in odor processing remains obscure. We examined functions of DA mediated by $\mathrm{D}_{2}$-like receptors in the olfactory bulb of adult zebrafish by pharmacology, whole-cell recordings, calcium imaging, and optogenetics. Bath application of DA had no detectable effect on odorantevoked sensory input. DA directly hyperpolarized mitral cells $(\mathrm{MCs})$ via $\mathrm{D}_{2}$-like receptors and slightly increased their response gain. Consistent with this effect on input- output functions of MCs, small odorant responses were suppressed, whereas strong responses were enhanced in the presence of DA. These effects increased the root-mean-square contrast of population activity patterns but did not reduce their correlations. Optical stimulation of interneurons expressing channelrhodopsin-2 evoked fast GABAergic inhibitory currents in mitral cells but failed to activate $\mathrm{D}_{2}$ receptor-mediated currents when stimuli were short. Prolonged stimulus trains, however, activated a slow hyperpolarizing current that was blocked by an antagonist of $\mathrm{D}_{2}$-like receptors. GABA and DA are therefore both released from interneurons by electrical activity and hyperpolarize $\mathrm{MCs}$, but $\mathrm{D}_{2}$-dependent dopaminergic effects occur on slower timescales. Additional effects of DA may be mediated by $\mathrm{D}_{1}$-like receptors. These results indicate that $\mathrm{DA}$ acts on $\mathrm{D}_{2}$-like receptors via asynchronous release and/or volume transmission and implicate DA in the slow adaptation of circuit function. The shift of the membrane potential away from spike threshold could adapt mitral cells to background input without compromising their sensitivity.

\section{Introduction}

The modulatory neurotransmitter dopamine (DA) mediates fundamental brain functions and is expressed in conserved clusters of neurons, most of which project over long distances (Wullimann and Mueller, 2004; Björklund and Dunnett, 2007). The retina and olfactory bulb $(\mathrm{OB})$, however, contain local interneurons that coexpress DA with the inhibitory neurotransmitter GABA (Gall et al., 1987; Byrd and Brunjes, 1995; Panzanelli et al., 2007; Parrish-Aungst et al., 2007). In the retina, DA is involved in the adaptation of sensory processing to slow changes in ambient light levels (Witkovsky, 2004), but its function in the OB remains unclear.

In the $\mathrm{OB}$, odorants evoke glutamatergic synaptic input to specific combinations of glomeruli. This input is transmitted to the principal neurons, the mitral cells (MCs) (in higher vertebrates also tufted cells) and to juxtaglomerular interneurons including external tufted cells, short-axon cells, and GABAergic periglomerular cells (K. Kosaka and T. Kosaka, 2005; ParrishAungst et al., 2007; Kiyokage et al., 2010; T. Kosaka and K.

\footnotetext{
Received Dec. 5, 2011; revised March 20, 2012; accepted March 22, 2012

Author contributions: S.T.B. and R.W.F. designed research; S.T.B. and Y.-P.Z.S. performed research; P.Z. contributed unpublished reagents/analytic tools; S.T.B. and R.W.F. wrote the paper.

This work was supported by the Novartis Research Foundation, the Max Planck Society, the Swiss Nationalfonds (SNF), the Deutsche Forschungsgemeinschaft (Sonderforschungsbereich 780), and stipends of the Boehringer Ingelheim Fonds (S.T.B.) and the SNF (Marie Heim-Vögtlin) (Y.-P.Z.S.). We thank Martin Naegeli and Estelle Arn Bouldoires for technical support, Wolfgang Driever for the TH antibody, and Johannes Letzkus for comments on this manuscript.

Correspondence should be addressed to Dr. Rainer W. Friedrich, Friedrich Miescher Institute for Biomedical Research, Maulbeerstrasse 66, 4058 Basel, Switzerland. E-mail: rainer.friedrich@fmi.ch.

DOI:10.1523/JNEUROSCI.6026-11.2012

Copyright $\odot 2012$ the authors $\quad 0270-6474 / 12 / 326830-11 \$ 15.00 / 0$
}

Kosaka, 2011). Interneurons mediate intraglomerular and interglomerular synaptic interactions that are thought to preprocess odor representations for higher-order computations. The only source of DA in the $\mathrm{OB}$ is a subpopulation of interneurons (DAINs) that have been classified as periglomerular cells or, more recently, as short-axon cells. DA-INs coexpress GABA as a neurotransmitter, receive input from sensory neurons, interact synaptically with MCs and interneurons in the same glomerulus, and project axons to other glomeruli (K. Kosaka and T. Kosaka, 2005; Parrish-Aungst et al., 2007; Kiyokage et al., 2010; T. Kosaka and K. Kosaka, 2011) (Fig. 1). DA-INs turn over throughout life (Hack et al., 2005; Adam and Mizrahi, 2011) and regulate the expression of tyrosine hydroxylase $(\mathrm{TH})$, the rate-limiting enzyme in DA synthesis, as well as a specific isoform of glutamate decarboxylase in an experience-dependent manner (Baker, 1990; Parrish-Aungst et al., 2011).

DA modulates sensory input to MCs in mammals and reptiles by acting on presynaptic $\mathrm{D}_{2}$-like receptors (Hsia et al., 1999; Wachowiak and Cohen, 1999; Berkowicz and Trombley, 2000; Ennis et al., 2001; Maher and Westbrook, 2008) and has been suggested to directly regulate $\mathrm{MC}$ activity via $\mathrm{D}_{2}$-like receptors in amphibians (Duchamp-Viret et al., 1997). In addition, DA can modulate synaptic transmission between MCs and interneurons (Brünig et al., 1999; Davila et al., 2003). However, it remains unclear how DA is released from interneurons and transmitted to its targets, and how it modulates information processing in the OB. We addressed these issues in the $\mathrm{OB}$ of adult zebrafish, which performs multiple computations including a regulation of the total MC activity (Tabor and Friedrich, 2008; Tabor et al., 2008) and a discrete decorrelation of MC activity patterns (Friedrich and 


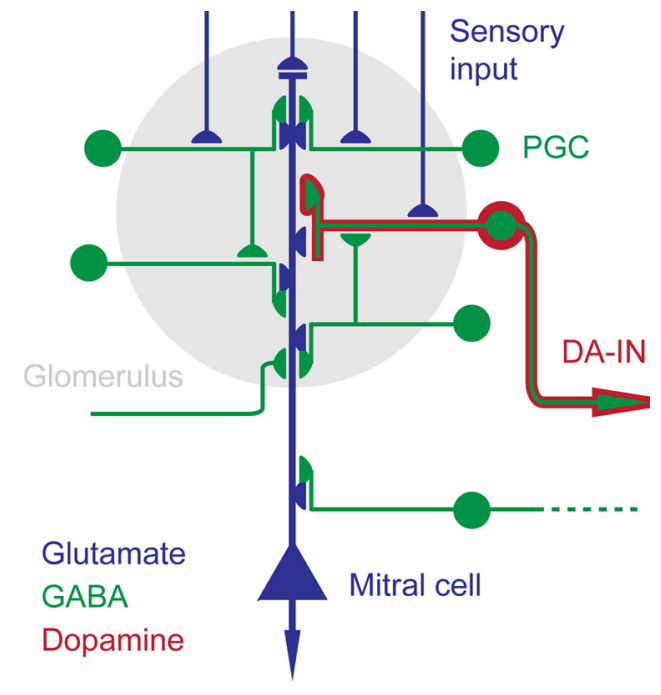

Figure 1. Schematic organization of glomerular neurons. Colors indicate neurotransmitter phenotypes. Sensory input is transmitted by glutamatergic sensory neurons to the principal neurons (mitral cells) and to subsets of juxtaglomerular neurons. DA is coexpressed with GABA in a subset of juxtaglomerular neurons (DA-INs) that project axons to distant glomeruli. Other juxtaglomerular neurons include different subtypes of GABAergic periglomerular cells (PGCS) and external tufted cells. External tufted cells are not shown in this diagram because they have not been described explicitly in fish. Synaptic connections have been drawn after the study by $\mathrm{K}$. Kosaka and T. Kosaka (2005). Gap junctions are not shown.

Laurent, 2001; Friedrich et al., 2004; Niessing and Friedrich, 2010; Wiechert et al., 2010). We find that DA is released by electrical activity and slowly hyperpolarizes $\mathrm{MCs}$ via $\mathrm{D}_{2}$-like receptors, suggesting volume transmission and/or asynchronous release. DA had opposing effects on the threshold and gain of input-output functions of MCs, and enhanced rootmean-square (rms) contrast of odorant-evoked activity patterns across MCs.

\section{Materials and Methods}

Animals, odor delivery, calcium imaging, and pharmacology. Adult zebrafish of both sexes ( $>3$ months of age) were used for all experiments. All experimental protocols were approved by the Veterinary Department of the Canton Basel-Stadt (Switzerland). Experiments were performed in an explant preparation of the intact brain and nose as described previously (Friedrich et al., 2006); an article describing the dissection procedure and the flow chamber in more detail is in preparation. Briefly, fish were decapitated under cold anesthesia, the ventral OB and telencephalon were exposed after removal of the eyes, and the preparation was placed into a custom-made flow chamber perfused with artificial CSF (ACSF) (Mathieson and Maler, 1988) at room temperature $\left(\sim 22^{\circ} \mathrm{C}\right)$ (Friedrich and Laurent, 2001). The flow chamber was perfused at a rate of $\sim 3 \mathrm{ml} / \mathrm{min}$ and had a volume of $<0.5 \mathrm{ml}$, allowing for fast exchange of solutions. Odor stimuli ( $\sim 2.5 \mathrm{~s}$ duration) were delivered through a constant stream of medium directed at the ipsilateral naris using a computercontrolled HPLC injection valve (Rheodyne). Odor stimuli were repeated at least three times in electrophysiological experiments and at least two times in imaging experiments. The interstimulus interval was at least $90 \mathrm{~s}$ in electrophysiological experiments and $120 \mathrm{~s}$ in imaging experiments to avoid adaptation. Results from multiple trials with the same stimulus were averaged.

Most optical and electrophysiological experiments were performed using a setup constructed around the body of an Olympus BX-51 fluorescence microscope. For two-photon microscopy, a custom-built unit containing galvanometric scanners $(6215 \mathrm{H}$; Cambridge Technology) and a scan lens was added externally. Fluorescence emission was projected onto photomultipliers (H7422P-40MOD; Hamamatsu) through a dichroic mirror immediately above the objective, emission filters, and custom detection optics. Blue light stimulation was performed using a strong LED (460 nm; Luxeon; Philips) mounted in the lamphouse of an epifluorescence lamp. Some experiments were performed using a microscope that was modified based on a design by Denk and colleagues (Euler et al., 2009) (MOM scope; Sutter Instrument). In this microscope, blue light stimulation was performed using a laser that was coupled into the microscope via a digital micromirror array and a dichroic mirror between the scanners and the scan lens (Blumhagen et al., 2011). In both setups, data acquisition was controlled by ScanImage and Ephus software (Pologruto et al., 2003; Suter et al., 2010). Conventional epifluorescence imaging was performed using standard attachments to the microscope body including a Xe arc lamp (Opti-Quip) and a sensitive CCD camera (CoolSnap; Photometrics).

Receptor neurons were loaded with Oregon Green 488 BAPTA-1 dextran (10 kDa; Invitrogen) as described previously (Friedrich and Korsching, 1997; Tabor et al., 2008). For two-photon calcium imaging, neurons in the OB were loaded by bolus injection of rhod-2-AM as described previously (Yaksi and Friedrich, 2006). Fluorescence of Yellow Cameleon 2.1 and rhod-2-AM was excited at $860 \mathrm{~nm}$ and detected simultaneously through bandpass filters $515 / 30$ and $610 / 75 \mathrm{~nm}$, respectively (Yaksi and Friedrich, 2006). Somatic odorant responses of MCs were quantified as the mean relative change in rhod-2 fluorescence after stimulus onset.

A transgenic line expressing Yellow Cameleon 2.1 under the control of a fragment of the HuC promoter (Park et al., 2000; Higashijima et al., 2003) was used to identify MCs. In the OB of adult fish, this line expresses the fluorescent marker predominantly or exclusively in MCs ( $\mathrm{Li}$ et al., 2005; Yaksi and Friedrich, 2006). Optogenetic experiments were performed using a transgenic line that expresses channelrhodopsin-2 fused to yellow fluorescent protein (Chr2YFP) under the control of dlx4/6 promoter/enhancer elements from zebrafish (Zerucha et al., 2000) and the tet-off system [Dlx4/6:itTA/Ptet:Chr2YFP Line 01 (Zhu et al., 2009)]. In the adult $\mathrm{OB}$, this line expresses Chr2YFP at high levels in interneurons of the glomerular layer (Zhu et al., 2009).

DA was applied in the presence of an antioxidant (ascorbate, 50 or 100 $\mu \mathrm{M})$. DA and $S-(-)$-sulpiride were obtained from Sigma-Aldrich; all other drugs were purchased from Tocris Bioscience. Wash-in and washout times were 5 and $10 \mathrm{~min}$, respectively, in electrophysiological experiments, and 10 and $15 \mathrm{~min}$, respectively, in imaging experiments.

Electrophysiology and optogenetics. Whole-cell recordings were performed using borosilicate pipettes $(6-18 \mathrm{M} \Omega)$ filled with an intracellular solution containing the following (in $\mathrm{mM}$ ): $130 \mathrm{~K}$-gluconate, $10 \mathrm{Na}$ gluconate, $10 \mathrm{Na}$-phosphocreatine, $4 \mathrm{NaCl}, 4 \mathrm{Mg}$-ATP, $0.3 \mathrm{Na}$-GTP, and 10 HEPES, pH 7.25. Alexa Fluor $594(50 \mu \mathrm{M})$ was added to visualize cell morphology under multiphoton optics. Data were acquired using a Multiclamp 700B amplifier (Molecular Devices) and Ephus software (Suter et al., 2010). Neurons were targeted by a combination of fluorescence and contrast-enhanced transmitted-light optics. Recordings were excluded from data analysis when the peak amplitude of action potentials dropped below $0 \mathrm{mV}$. Measurements were not corrected for the liquid junction potential. For recordings of odorant responses, odorants evoking responses were selected from a panel of six amino acids (Ala, Ser, His, Met, Leu, Lys; $10 \mu \mathrm{M})$ and their mixtures for each cell. Channelrhodopsin-2 was activated by pulses of blue light illuminating a substantial area around the recorded neuron. In both setups, light power under the objective was $\sim 250-300 \mu \mathrm{W} / \mathrm{mm}^{2}$.

Input resistance was measured using $2 \mathrm{~s}$ hyperpolarizing current injections (usually $25 \mathrm{pA}$ ). Membrane potential was then averaged over the last second preceding the current step and the last second during the current step. Each measurement was repeated at least three times, and results were averaged. Spontaneous firing rates and baseline membrane potential were measured during $10 \mathrm{~s}$ periods without current injection. In all cases except for the time course data (see Fig. $4 B$ ), measurements were repeated at least three times. In some experiments, not all neurons could be held until the end of the washout period. In these cases, the number of neurons recorded during washout is reported separately in the figure legends.

Immunocytochemistry. Brains were fixed in 2\% Formal-Fixx (Thermo Fisher Scientific) in PBS for $12-48 \mathrm{~h}$ at $4^{\circ} \mathrm{C}$, cryoprotected in $30 \%$ su- 

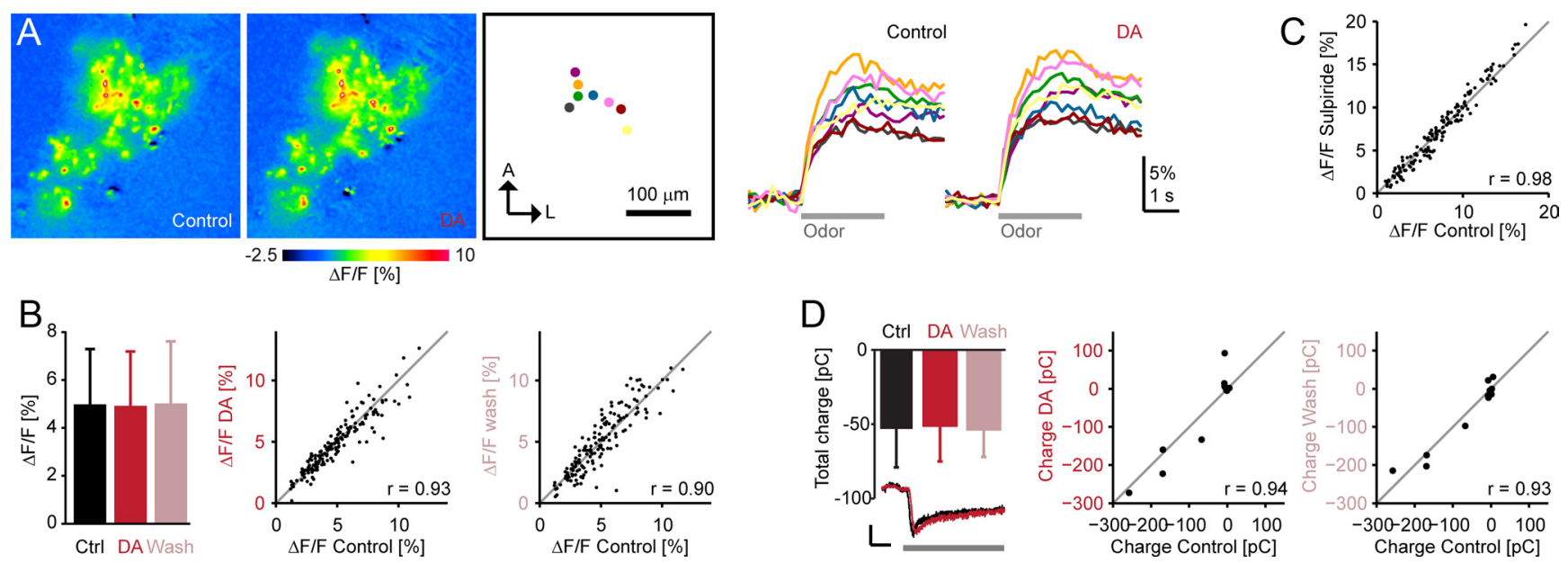

Figure 2. DA has no detectable effect on sensory input. $A$, Left, 0 dorant-evoked calcium signals in sensory afferents before and during bath application of $\mathrm{DA}$, averaged between 0.5 and $5.8 \mathrm{~s}$ after response onset. Right, Time course of calcium signals in selected glomerular foci. Position of foci is shown in the map. $\boldsymbol{B}$, Mean calcium signal ( \pm SD) before, during, and after DA application, calcium signals of individual glomerularfoci before and during the presence of DA, and calcium signals before and after washout of DA ( $n=157 \mathrm{glomerularfoci} \mathrm{in} 6$ fish). $C$, Comparison of calcium signals from individual glomerularfoci $(n=$ 154) before and during exposure to sulpiride. $D$, Mean odorant-evoked charge transfer in MCs ( \pm SEM) and comparison of charge transfer in individual MCs before, during, and after application of DA ( $n=25$ M(s; washout, $n=13)$. Data are shown only for those neurons that were held until end of the wash-out period. Traces show examples of odorant-evoked currents. Calibration: $50 \mathrm{pA}, 1 \mathrm{~s}$.

crose, embedded in M-1 matrix (Thermo Fisher Scientific), quickly frozen, and sectioned at 14 or $20 \mu \mathrm{m}$ on a cryostat. Antibodies used were a rabbit anti-TH antibody (provided by W. Driever, University of Freiburg, Freiburg, Germany) at a dilution of 1:560 in AB diluting solution (Ventana), mouse anti-TH (Millipore; MAB318; 1:800), chicken anti-GFP (Invitrogen; A10262; 1:800), rabbit anti-GFP (Invitrogen; A11122; 1:800), and secondary antibodies conjugated to Alexa chromophores (Invitrogen; 1:800). Stained sections were washed with warm water containing a detergent, dehydrated in ascending ethanol concentrations, soaked in UltraClear solution (Medite Medizintechnik AG) and mounted using ProLong Gold antifade reagent (Invitrogen). Images were taken with an LSM 510 inverted confocal laser-scanning microscope equipped with a Plan-Neofluar $40 \times$ oil-immersion objective (NA 1.3, Zeiss).

Data analysis. Relative changes in fluorescence of MC somata was quantified in a time window $0.9-5.8 \mathrm{~s}$ after stimulus onset. This relatively long time window was chosen because calcium transients evoked by individual action potentials in mitral cells decay with a time constant of 3-4 s (Yaksi and Friedrich, 2006). Thus, the calcium signal effectively integrates neural activity primarily from an early phase of the time window. Moreover, a longer time window reduces measurement noise because it increases the number of detected photons. Using shorter time windows produced no qualitative change in the results. In addition, we temporally deconvolved the measured calcium signals to reconstruct the underlying firing rate changes of each individual neuron (Yaksi and Friedrich, 2006) and analyzed these data using shorter time windows. Again, results were not qualitatively different. We therefore report only the results obtained with the standard time window applied to the non-deconvolved data.
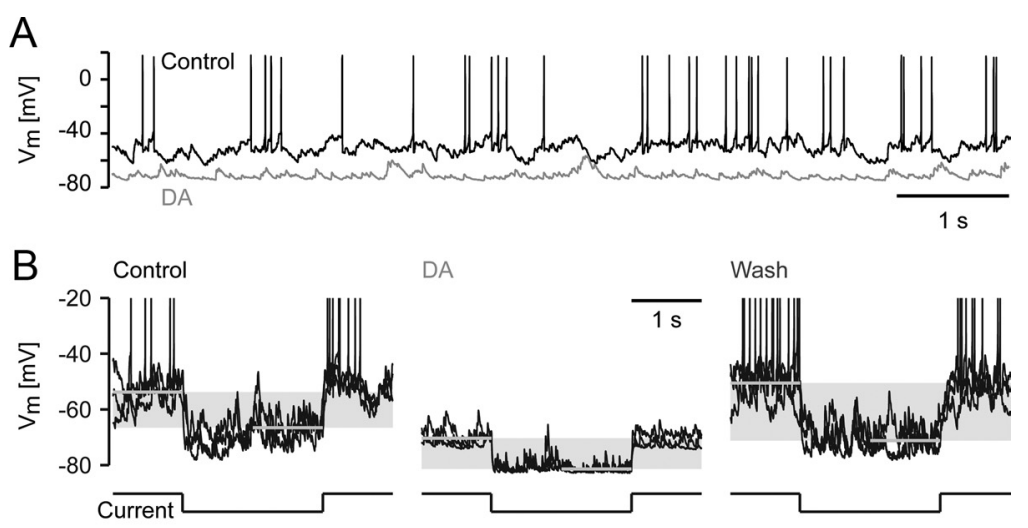

DA
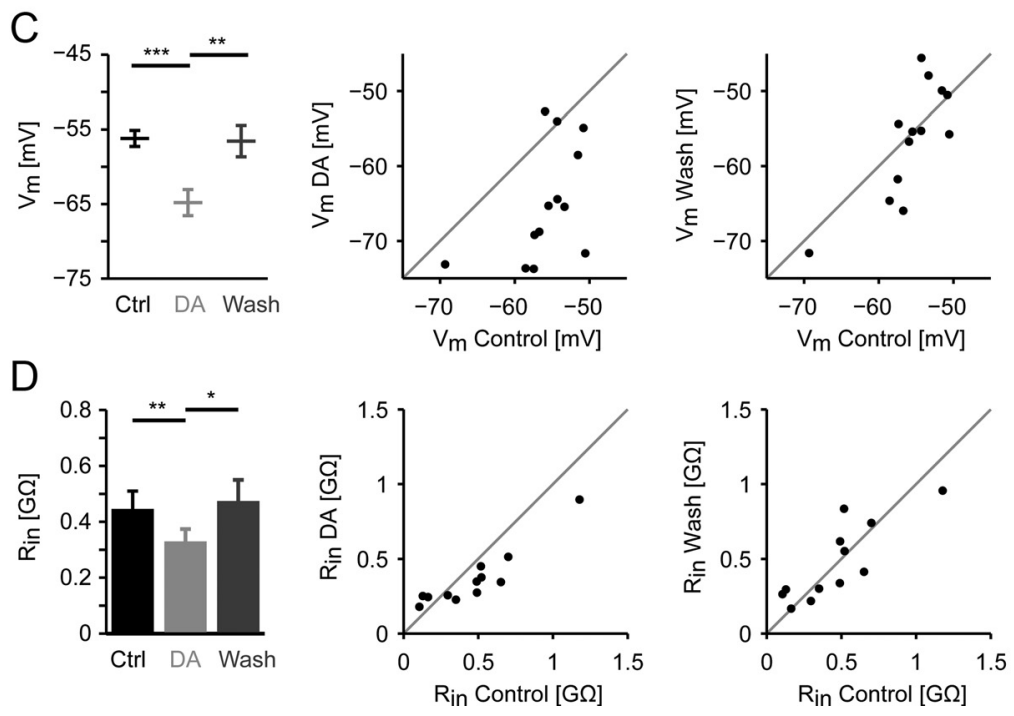

Figure 3. Effects of DA on MCs. $\boldsymbol{A}$, Whole-cell recording of spontaneous activity of a $M C$ before and during exposure to $D A$. $\boldsymbol{B}$, Responses of a MC to current injection ( $-25 \mathrm{pA} ; 2 \mathrm{~s}$ ) before, during, and after exposure to DA (overlay of 3 trials; action potentials are clipped). The horizontal gray lines indicate mean membrane potential during $1 \mathrm{~s}$ periods immediately before and at the end of the current step. The shaded area shows difference between mean membrane potential measurements used to calculate input resistance. $C$, Left, Mean effect ( \pm SEM) of DA on resting membrane potential ( $n=18$; washout, $n=13$ ). Scatter plots compare membrane potential of individual neurons before and during application of DA, and before and after application of DA. Data are shown only for those neurons that were held until end of the washout period. The horizontal lines indicate statistically significant differences; all other comparisons were not significant. $D$, Effect of DA on input resistance ( $n=17$; washout, $n=12$ ). Error bars show SEM. The horizontal lines indicate statistically significant differences; all other comparisons were not significant. ${ }^{*} p<0.05 ;{ }^{* *} p<0.01 ;{ }^{* * *} p<0.001$. 

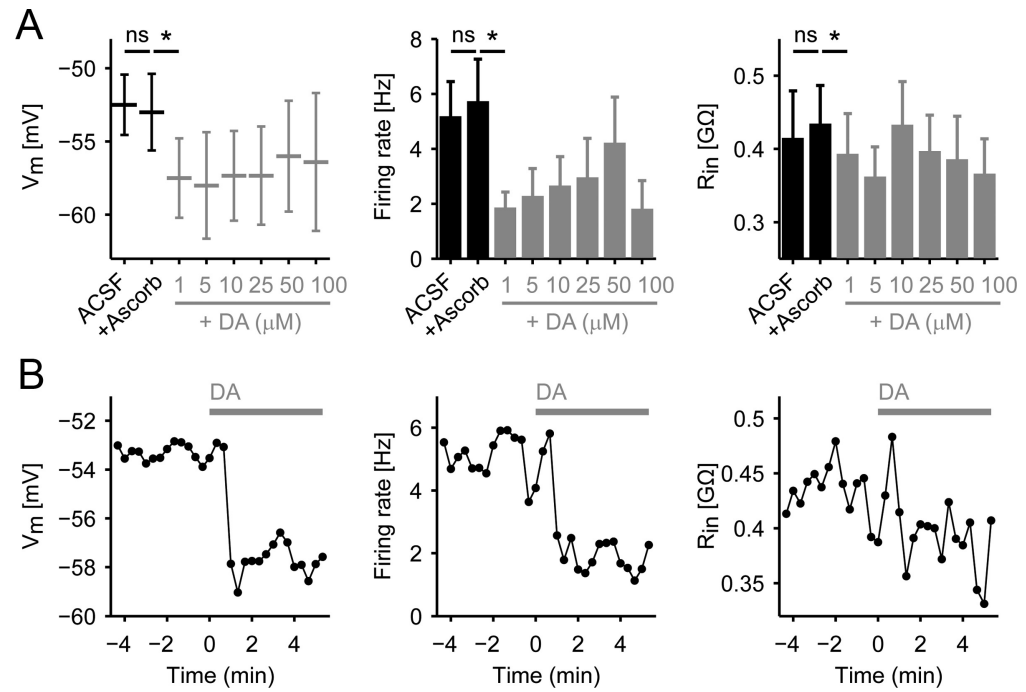

Figure 4. Dose dependence and time course of the effects of DA. A, Mean membrane potential, firing rate, and input resistance ( \pm SEM) as a function of DA concentration $(n=6 \mathrm{MCS})$. ASCF, No drugs. Ascorb, Addition of ascorbate (100 $\mu \mathrm{m}$ ), an antioxidant that was coapplied routinely with DA. Gray, Increasing concentrations of DA in the presence of ascorbate. Results obtained in the presence of ascorbate alone were statistically compared with data obtained in the absence of drugs, and with data obtained in the presence of the lowest concentration of DA $(1 \mu \mathrm{M})$. ns, Not significant; ${ }^{*} p<0.05$. B. Time course of effects (mean over $n=6 \mathrm{MCs}$ ). Membrane potential, firing rate, and input resistance were measured every 20 s. Bath perfusion was switched from ACSF/ascorbate to ACSF/ascorbate plus DA $(1 \mu \mathrm{m})$ at $t=0$.

Throughout this manuscript, correlation was calculated as the Pearson product-moment correlation. SDs and correlations of time-averaged, odorant-evoked activity patterns before and during exposure to DA were calculated based on vectors representing the mean firing rates or calcium signals of each neuron. For electrophysiological data, values reported in the text were obtained by averaging firing rates over an analysis time window spanning the first $500 \mathrm{~ms}$ of the odorant response. SDs and correlations of time-resolved activity patterns were calculated based on matrices (neurons by time) representing the firing rates of each neuron in $100 \mathrm{~ms}$ bins. Different analysis time windows gave similar results. Using an analysis time window of $1000 \mathrm{~ms}$, correlations were 0.71 for timeaveraged patterns and 0.59 for time-resolved patterns. SDs (rms contrast) increased from $7.2 \mathrm{~Hz}$ in the absence of $\mathrm{DA}$ to $17.3 \mathrm{~Hz}$ in the presence of DA for time-averaged activity patterns $\left(p<10^{-5} ; F\right.$ test or Bartlett's test), and from 10.8 to $21.2 \mathrm{~Hz}$ for time-resolved activity patterns $\left(p<10^{-10} ; F\right.$ test or Bartlett's test). Using an analysis time window of $2000 \mathrm{~ms}$, correlations were 0.65 for time-averaged patterns and 0.56 for time-resolved patterns. SDs (rms contrast) increased from $5.1 \mathrm{~Hz}$ in the absence of DA to $13.3 \mathrm{~Hz}$ in the presence of DA for time-averaged activity patterns ( $p<10^{-5} ; F$ test or Bartlett's test), and from 8.4 to 17.0 $\mathrm{Hz}$ for time-resolved activity patterns $\left(p<10^{-10} ; F\right.$ test or Bartlett's test).

Firing rates for input-output curves were measured in a time window 1-2 s after current onset to avoid transients. To fit lines to input-output curves, individual curves were interpolated using a piecewise cubic Hermite interpolation algorithm. Data points left of the first zero point and right of the maximum were excluded. The latter were excluded because large currents sometimes drove neurons into depolarization block. The linear fit was then performed within the interval between 10 and $90 \%$ of the maximum. Other fitting strategies produced similar results.

To calculate differences between probability distributions of response intensities (see Figs. 7F, 8D), histograms of the number of responses as a function of response intensity were generated using bins of $2 \mathrm{~Hz}$ (electrophysiological data) or $2 \% \Delta F / F$ (multiphoton calcium imaging data). Histograms obtained under control conditions were then subtracted from histograms obtained in the presence of DA. The resulting difference histograms were smoothed by a low-pass Butterworth filter (roll-off, $\sim 7$ bins) and normalized to the integrated absolute difference. The absolute values in each difference histogram therefore sum up to unity.
Significance tests were performed using a nonparametric sign rank test, unless noted otherwise.

\section{Results \\ Effects of DA on sensory afferents}

We focused on effects of DA mediated by $\mathrm{D}_{2}$-like receptors, the main class of DA receptors in the OB (Nickell et al., 1991; Coronas et al., 1997; Duchamp-Viret et al., 1997; Davila et al., 2003; GutièrrezMecinas et al., 2005). $\mathrm{D}_{2}$-like DA receptors have been detected on sensory afferents, MCs, and interneurons (Nickell et al., 1991; Coronas et al., 1997; Duchamp-Viret et al., 1997; Davila et al., 2003; Gutièrrez-Mecinas et al., 2005). On sensory afferents, $\mathrm{D}_{2}$-like receptors have been detected in mammals (Nickell et al., 1991; Coronas et al., 1997; GutièrrezMecinas et al., 2005) but not in amphibians (Duchamp-Viret et al., 1997), suggesting that effects of DA on sensory input differ between species. In mammals and turtles, DA or agonists of $\mathrm{D}_{2}$-like receptors reduced MC responses to olfactory nerve stimulation via a presynaptic mechanism and decreased presynaptic calcium influx into sensory axon terminals (Hsia et al., 1999; Wachowiak and Cohen, 1999; Berkowicz and Trombley, 2000; Ennis et al., 2001; Maher and Westbrook, 2008). We therefore examined whether DA modulates transmitter release from sensory afferents also in zebrafish.

We first loaded sensory neurons with a calcium indicator (Oregon Green 488 BAPTA-1 dextran) and measured odorantevoked fluorescence changes in axon terminals with a CCD camera. Olfactory stimulation with mixtures of three amino acids (10 $\mu \mathrm{M}$ each) evoked discrete patterns of calcium signals, reflecting sensory input to specific combinations of glomeruli (Fig. 2A) (Friedrich and Korsching, 1997; Tabor et al., 2008). Previous studies using this method detected reductions in calcium signals by a $\mathrm{D}_{2}$ receptor agonist in turtles (Wachowiak and Cohen, 1999) and by $\mathrm{GABA}_{\mathrm{B}}$ receptor agonists in multiple species including zebrafish (Wachowiak and Cohen, 1999; McGann et al., 2005; Tabor et al., 2008). However, we found that the mean response in the presence of DA $(100 \mu \mathrm{M})$ was not significantly different from the mean response in the absence of DA ( $n=157$ glomerular foci in 6 fish; Fig. 2 B). The Pearson correlation between responses of individual neurons in the presence and in the absence of DA was high ( $r=0.93 ; 95 \%$ confidence range, $0.90-0.94)$, and not lower than the correlation between responses before and after washout of DA ( $r=0.90$; 95\% confidence range, 0.86-0.93; Fig. $2 B$ ). Similarly, we found no significant effect of sulpiride (50 $\mu \mathrm{M})$, an antagonist of $\mathrm{D}_{2}$-like DA receptors, on odorant-evoked calcium signals (Fig. 2C). The mean responses before and during application of sulpiride were not significantly different $(n=154$ glomerular foci in 5 fish), and the correlation between odorant responses before and during the presence of sulpiride ( $r=0.98$; 95\% confidence range, 0.98-0.99) was not lower than the correlation between responses before and after sulpiride application $(r=$ 0.96; 95\% confidence range, $0.94-0.97)$.

To examine whether DA affects odorant-evoked synaptic input from sensory neurons to MCs, we performed whole-cell 
voltage-clamp recordings at a holding potential near the reversal potential of chloride currents $(-70 \mathrm{mV})$. No significant change in the total charge transmitted during the first $2 \mathrm{~s}$ of an odorant response was detected in the presence of DA $(n=$ 25; one odorant per MC; Fig. 2D). The correlation between charge transfer in individual neurons before and during the presence of DA was high $(r=0.94 ; 95 \%$ confidence range, 0.81-0.98), and not lower than the correlation between responses before and after washout of DA $(r=0.93$; 95\% confidence range, $0.78-$ 0.98; Fig. 2D). These results indicate that, unlike in rodents and turtles, DA does not modulate transmitter release from olfactory sensory neurons in zebrafish.

\section{Direct effects of DA on mitral cells}

We next examined effects of DA (50 or $100 \mu \mathrm{M}$, in the presence of an equimolar concentration of ascorbate) on MCs. In whole-cell current-clamp recordings, DA hyperpolarized MCs and reduced spontaneous firing (Fig. $3 A, B$ ). On average, resting potentials were decreased from $-56.2 \pm 4.6 \mathrm{mV}$ (mean $\pm \mathrm{SD}$ ) to $-64.8 \pm 7.4 \mathrm{mV}(n=18 \mathrm{MCs} ; p<$ 0.001; Fig. 3C), and spontaneous firing was reduced from $2.6 \pm 2.6$ to $0.3 \pm 0.7$ $\mathrm{Hz}(n=18 ; p<0.001)$. Consistent with this observation, DA reduced the holding current in voltage-clamp recordings at $-70 \mathrm{mV}$ from $-68 \pm 71$ to $-46 \pm$ 65 pA $(n=16$ MCs; $p<0.005)$. Moreover, DA decreased the input resistance from $445 \pm 263$ to $330 \pm 182 \mathrm{M} \Omega(n=$ $17 ; p<0.01$; Fig. $3 B, D)$. These effects were observed in almost all individual mitral cells and reversible after washout (Fig. 3C,D).

In a smaller number of MCs $(n=6)$, we examined the dose dependence of these effects between 1 and $100 \mu \mathrm{M}$ DA. Effects of DA were pronounced and statistically significant already at the lowest concentration tested $(1 \mu \mathrm{M}$ DA; Fig. $4 A)$. Ascorbate $(100 \mu \mathrm{M})$, which was routinely coapplied with DA as an antioxidant, had no effect (Fig. $4 A$ ). All effects of DA developed and stabilized within 2 min of wash-in (Fig. 4B), confirming that our standard wash-in times ( 5 or $10 \mathrm{~min}$ ) were sufficient to reach equilibrium.

To examine whether DA acts directly on MCs, we blocked glutamatergic synaptic transmission using the AMPA/kainate and NMDA receptor antagonists NBQX $(5 \mu \mathrm{M})$ and APV $(50 \mu \mathrm{M})$, respectively ( $n=9 \mathrm{MCs}$ in 3 fish), which almost completely abolished spontaneous synaptic inputs and action potential firing of MCs ( Tabor and Friedrich, 2008). In further experiments ( $n=6 \mathrm{MCs}$ in 2 fish), $\mathrm{GABA}_{\mathrm{A}}$ and $\mathrm{GABA}_{\mathrm{B}}$ receptors were also blocked by Gabazine $(5 \mu \mathrm{M})$ and $\left[S-\left(R^{\star}, R^{\star}\right)\right]$-[3-[[1-(3,4-dichlorophenyl)ethyl]amino]2-hydroxypropyl] (cyclohexylmethyl)phosphinic acid (CGP 54626) $(5 \mu \mathrm{M})$, respectively. No obvious additional effects were observed, and data were therefore pooled (total of $15 \mathrm{MCs}$ from 5 fish). Under these conditions, DA still significantly and reversibly reduced the resting potential (from $-59.3 \pm 6.5$ to $-66.8 \pm 5.0 \mathrm{mV} ; p<10^{-4}$ ) and input resistance (from $652 \pm 401$ to $451 \pm 378 \mathrm{M} \Omega ; p<10^{-3}$; Fig. $5 A-C)$. Spontaneous action potential firing was already low in the absence of DA $(0.3 \pm 0.6 \mathrm{~Hz})$ and reduced to zero in the presence of DA.

Sulpiride had no consistent effect on membrane potential or input resistance when applied alone ( $n=14 \mathrm{MCs}$; Fig. $5 D)$. However, it completely blocked effects of DA on membrane potential and partially reversed effects on input resistance (tested in $n=12$ of $15 \mathrm{MCs}$; Fig. $5 \mathrm{~B}, \mathrm{C}$ ). These results indicate that DA acts directly on $\mathrm{MCs}$ via $\mathrm{D}_{2}$-like receptors. Additional mechanisms such as effects mediated by $\mathrm{D}_{1}$-like receptors may also be involved since sulpiride did not completely antagonize the effect of DA on input resistance.

We next measured firing rate output as a function of injected input current in the absence of synaptic blockers to examine how 

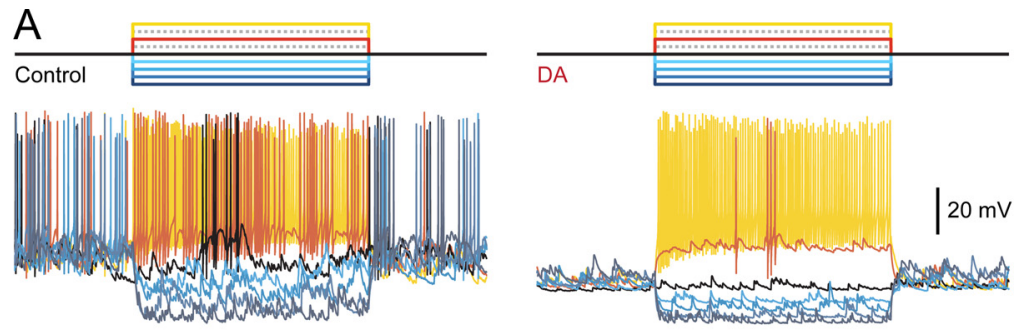

B
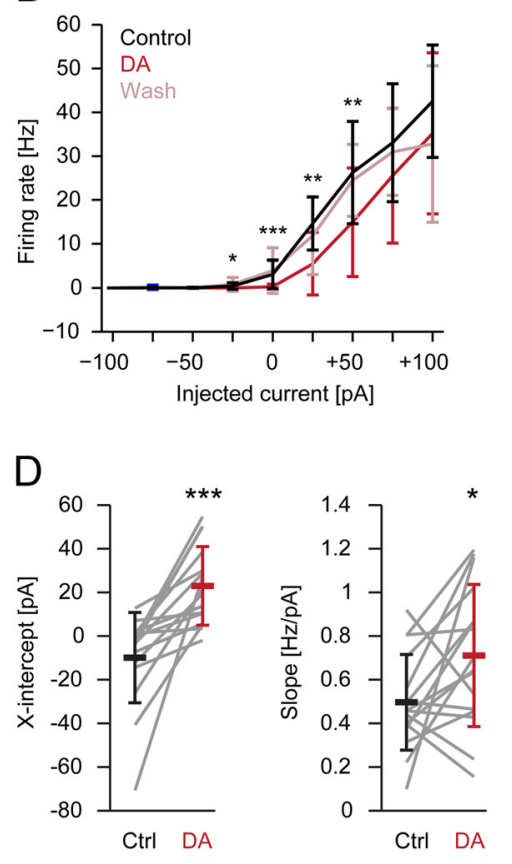

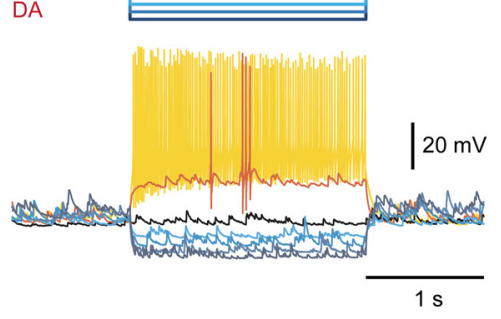

C
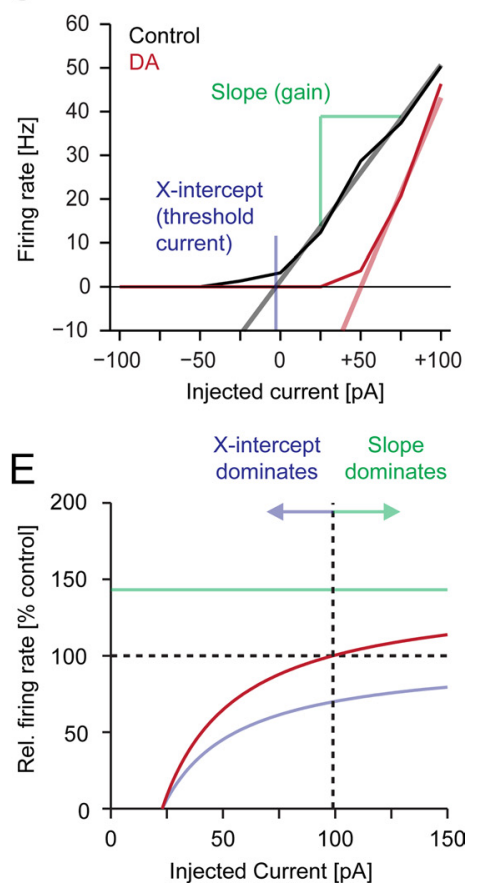

Figure 6. Effects of DA on input- output functions. $\boldsymbol{A}$, Responses of a MC to current injection ( $2 \mathrm{~s} ;-100$ to $100 \mathrm{pA}$ in $25 \mathrm{pA}$ steps) before and during exposure to DA. $\boldsymbol{B}$, Firing rate output as a function of input current, averaged over all recorded $\operatorname{MCs}(n=17)$. Error bars show SD. The asterisks indicate significant differences in firing rate before and during exposure to DA. $\boldsymbol{C}$, Example of input-output functions measured in an individual $M C$ and line fits to the rising flank. $\boldsymbol{D}$, Changes in $x$-intercept and slope of input- output functions. The horizontal bars show mean \pm SD; the gray lines show changes of individual MCs. $E$, Predicted effects of threshold shift ( $x$-intercept; blue), gain change (slope; green), and their combination (red) on output firing rate relative to control (100\%) as a function of input current. At the current indicated by the dashed line, output firing rates start to exceed control because the gain change becomes dominant. ${ }^{* * *} p<0.001 ;{ }^{* *} p<0.01 ;{ }^{*} p<0.05$.

DA modulates input-output functions of MCs (Fig. 6A). One possibility is that the input-output curve is shifted along the $x$-axis (input current) without a change in slope. Such an additive modulation changes the threshold current required to elicit action potentials (rheobase), but not the sensitivity to suprathreshold inputs (gain). Alternatively, DA may change the slope (gain) of the input-output curve, resulting in a multiplicative scaling of the sensitivity and dynamic range (Holt and Koch, 1997; Chance et al., 2002). Both these effects can also occur in combination (Rothman et al., 2009; Weber et al., 2010). MC firing started, on average, at $-25 \mathrm{pA}$ and increased almost linearly with current amplitude ( $n=17 \mathrm{MCs}$ ). In the presence of DA, the average input-output function was shifted to the right by $\sim 30 \mathrm{pA}$ (Fig. $6 B)$. To analyze effects in individual MCs, we fitted lines to the rising phase of each input-output curve and measured the slopes and $x$-intercepts ( $n=16$ successful fits; sigmoid fits gave similar results; Fig. $6 C$ ). In all MCs, DA shifted the $x$-intercept to the right (control, $-9.9 \pm 20.7 \mathrm{pA}$; DA, $22.9 \pm 18.0 \mathrm{pA} ; p<0.001$; Fig. $6 D$ ). The mean slope also increased significantly from $0.50 \pm$
0.22 to $0.71 \pm 0.33 \mathrm{~Hz} / \mathrm{pA}(p<0.05)$, although effects on individual MCs were heterogeneous (Fig. 6D). Similar effects of DA were observed in additional MCs recorded in the presence of synaptic blockers (NBQX and APV or NBQX, APV, Gabazine, and CGP 54626; $n=12$ MCs): the mean $x$-intercept increased from $-5.0 \pm 14.5 \mathrm{pA}$ (control) to $25.8 \pm$ $23.3 \mathrm{pA}$ (DA; $p<0.001$ ), and the mean slope increased from $0.60 \pm 0.26 \mathrm{~Hz} / \mathrm{pA}$ (control) to $0.80 \pm 0.26 \mathrm{~Hz} / \mathrm{pA}(\mathrm{DA} ; p<$ 0.05; data not shown). The finding that DA slightly increased response gain but decreased input resistance could be explained, at least in part, by opposing effects of input resistance on the sensitivity to input current and on the membrane time constant (Holt and Koch, 1997; Chance et al., 2002).

The rightward shift of the input-output function decreases MC firing, while the slight increase in the slope tends to increase MC firing. To predict the consequences of these effects individually and in combination, we used the averaged fit parameters to calculate expected firing rates in the presence of DA relative to control as a function of input current. When only the shift of the $x$-intercept is considered, firing rate output of MCs is completely suppressed for small input currents and asymptotically approaches control as input current is increased (Fig. $6 E$, blue). The effect on the slope alone increases firing rates by a constant factor, independent of injected currents (Fig. 6E, green). When both effects are combined, firing rate is decreased for small input currents because the effect on the $x$-intercept dominates. At high input currents, however, firing exceeds control because the multiplicative effect of the slope becomes more pronounced (Fig. $6 E$, red). Similar results were obtained for data recorded in the presence of synaptic blockers. The modulatory effect changes from suppression to enhancement when input currents reaches $\sim 100 \mathrm{pA}$ (Fig. $6 E$ ), corresponding, under steady-state conditions, to a firing rate increase of $\sim 40 \mathrm{~Hz}$ (Fig. $6 \mathrm{~B}$ ). In voltage-clamp recordings from MCs at a holding potential of $-70 \mathrm{mV}$, odorants evoked input currents up to $\sim 300 \mathrm{pA}$ (absolute value averaged over the first $2 \mathrm{~s}$ ), although most currents were $<100 \mathrm{pA}$ ( $n=25 \mathrm{MCs}$; data not shown). Our calculations thus suggest that DA may suppress weak, but enhance strong, MC activity during an odorant response. However, the strong inhibitory input during an odorant responses will also affect input-output functions of MCs. It is therefore not possible to predict the effect of DA on odorant responses of MCs in a quantitative manner based on the measured input-output functions.

\section{Effects of DA on odor responses}

If the effect of DA on input-output functions of MCs is functionally relevant, a signature of it may be observed in odorant-evoked 

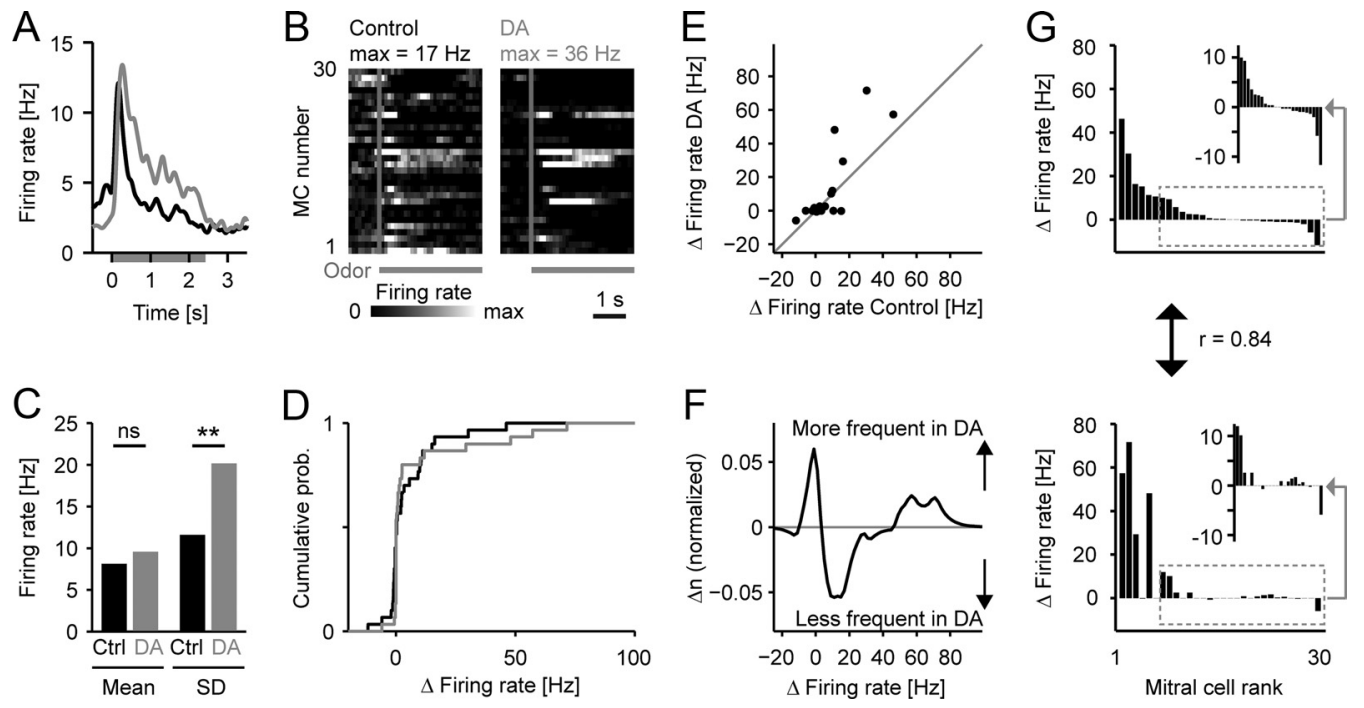

Figure 7. Effect of DA on odorant-evoked activity measured by electrophysiology. $A$, Mean odorant-evoked firing rate before (black) and during (gray) exposure to DA ( $n=30 \mathrm{MCs} ; 1$ odorant each) as a function of time. $B$, Firing rates of all individual $M C$ s before and during exposure to DA as a function of time ( $100 \mathrm{~ms}$ time bins). Grayscale is normalized to the mean of the $10 \%$ largest firing rates in each plot (control, $17 \mathrm{~Hz}$; DA, $36 \mathrm{~Hz}$ ); gray bar indicates odorant application. C, Mean (left) and SD (right) of time-averaged MC firing rates before and during exposure to DA. Statistical differences between SDs were assessed using an $F$ test or Bartlett's test. ${ }^{* *} p<0.01$. D. Cumulative distributions of odorant-evoked firing rate changes before and during exposure to DA. $\boldsymbol{E}$, Comparison of odorant-evoked firing rate changes before and during exposure to DA in each individual MC. $F$, Difference between the distributions of odorant-evoked firing rate changes before and during exposure to DA. The distribution of firing rate changes under control conditions was subtracted from the distribution obtained in the presence of DA, and the difference was normalized to the integrated absolute difference. Positive and negative values indicate that responses of a given amplitude were more frequently and less frequently observed in the presence of DA, respectively. $\boldsymbol{G}$, Odorant-evoked firing rate changes of individual MCs before (top) and during (bottom) exposure to DA, ranked by magnitude before DA. Insets, Enlarged view of subregion outlined by dashed box. $r$, Pearson correlation coefficient.

activity patterns even though quantitative predictions are not possible. To test this hypothesis, we first recorded responses of MCs to amino acid odorants $(10 \mu \mathrm{M})$ or their mixtures in current clamp ( $n=30 \mathrm{MCs}$; one odorant per MC). In the presence of DA, baseline firing was reduced, whereas the average odorant response was slightly delayed, increased, and prolonged (Fig. 7A,B). Mean firing rates within a $500 \mathrm{~ms}$ window around the peak increased from $8.1 \pm$ $11.6 \mathrm{~Hz}$ (control) to $9.7 \pm 20.2 \mathrm{~Hz}$ in the presence of DA, but this effect was not statistically significant. The SD of responses across the population, however, increased significantly from 11.6 to $20.2 \mathrm{~Hz}$ $(p<0.01 ; F$ test or Bartlett's test; Fig. 7C).

To examine these effects in more detail, we analyzed the cumulative probability distributions of response amplitudes (Fig. $7 D$ ), compared responses of individual neurons before and during DA application (Fig. 7E), and computed the difference between the distributions of response amplitudes (Fig. 7F). These analyses revealed distinct effects of DA depending on the response amplitude under control conditions: (1) negative firing rate occurred less frequently in the presence of DA, (2) response amplitudes near zero occurred more frequently, (3) small positive response amplitudes occurred less frequently, and (4) large positive responses occurred more frequently. Hence, DA reduced small but enhanced large odorant responses, consistent with its effect on input-output functions. An enhancement of responses was observed, on average, when responses exceeded $40 \mathrm{~Hz}$ under control conditions (Fig. 7F). This is in good agreement with the predictions based on input-output functions (Fig. 6E), despite the fact that input-output functions were measured under conditions of spontaneous activity.

The significant increase in the SD of responses across the recorded MC population reflects a shift of individual response amplitudes toward extremes (values near zero or very large values). In first approximation, this effect can be interpreted as an increase in the contrast of the activity pattern. Indeed, the SD of the population activity pattern is equivalent to the rms contrast, a generic contrast measure that is independent of the spatial structure of an image (Peli, 1990). A systematic change in rms contrast does not redistribute activity across the population of neurons, implying that response patterns before and during exposure to DA should be closely related. Indeed, the Pearson correlation coefficient of time-averaged response patterns before and during exposure to DA was high ( $r=0.84$; Fig. $7 G)$.

To assess whether DA affected the temporal evolution of the population response, we performed the same analyses on timeresolved activity patterns (matrix of MCs vs time; Fig. 7B). As for time-averaged responses, time-resolved activity patterns evoked in the absence or presence of DA were highly correlated $(r=0.66)$ but the SD increased significantly (from $14.1 \mathrm{~Hz}$ in the absence of DA to $23.5 \mathrm{~Hz}$ in the presence of DA; $p<10^{-8}$; F test or Bartlett's test). Similar results were obtained using different analysis time windows (see Materials and Methods). Hence, DA changed the amplitude distribution of response patterns, which resulted in an increased rms contrast, but had only modest effects on the cellby-cell structure of MC activity patterns (Fig. $7 B, G$ ).

We further examined effects of DA on odorant-evoked activity patterns by multiphoton calcium imaging after bulk loading of the red fluorescent calcium indicator, rhod-2-AM. MCs were identified by a fluorescent transgenic marker (Yaksi and Friedrich, 2006), and responses were quantified as the time-averaged relative change in somatic fluorescence intensity $(\Delta F / F$; Fig. $8 A)$. This approach allowed us to measure responses from larger populations of MCs $(n=$ 112 MCs from 8 fish) to three similar amino acid odorants (Ala, Ser, His; $10 \mu \mathrm{M})$. A limitation of this approach, however, is that the baseline activity of individual neurons cannot be determined, thus precluding absolute activity measurements. Moreover, noise in optical measurements tends to obscure small effects. Effects of DA on odorant-evoked activity patterns are therefore expected to be less pronounced when measured by multiphoton calcium imaging compared with electrophysiology. 
A
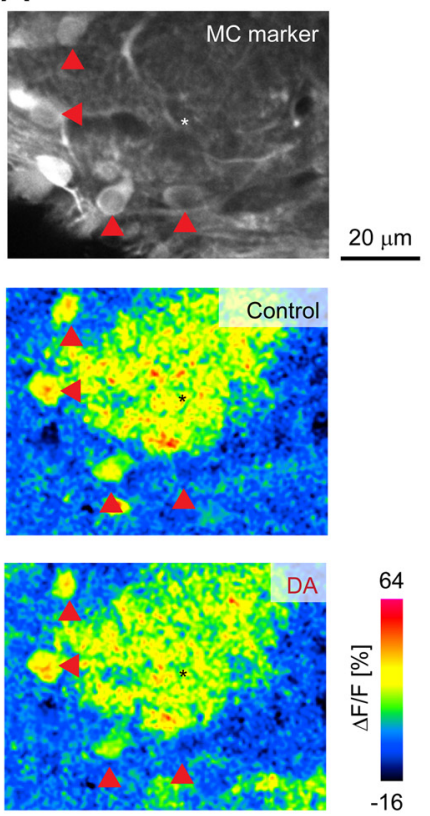

B

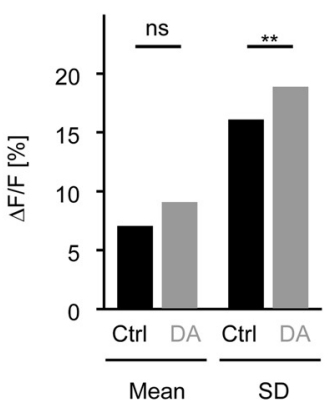

$\mathrm{F}$

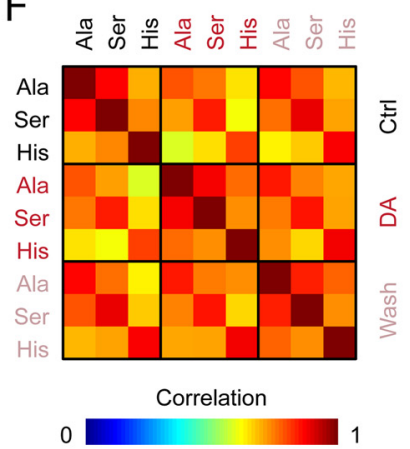

C

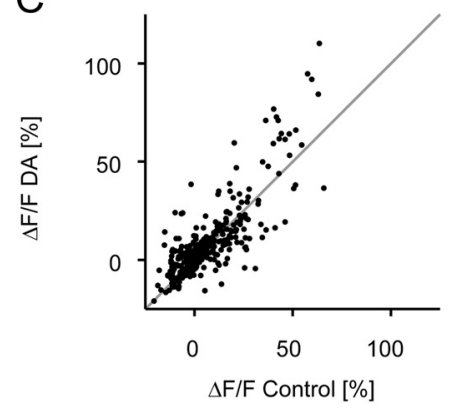

D

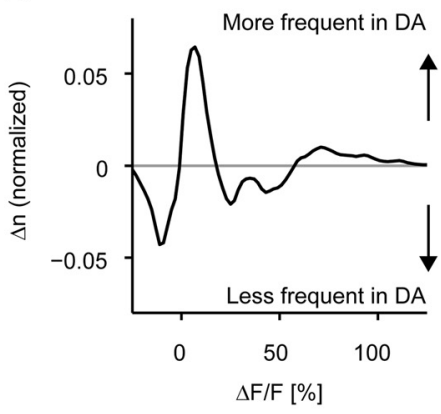

E
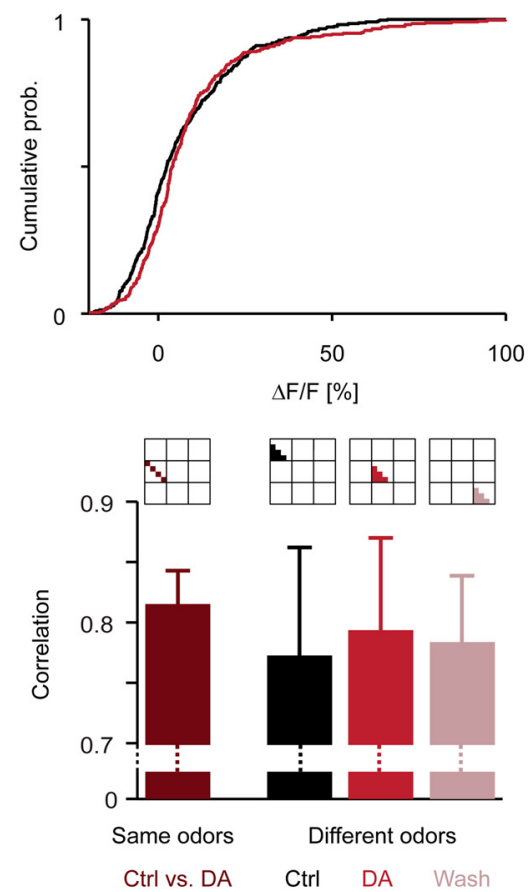

Figure 8. Effect of DA on odorant-evoked activity patterns measured by multiphoton calcium imaging. $A$, Examples of odorantevoked calcium signals measured by multiphoton microscopy in MCs. Top, Transgenic expression of MC marker. The arrowheads show four MCs; the asterisk labels a glomerulus. $\boldsymbol{B}$, Mean (left) and SD (right) of odorant-evoked calcium signals across MCs before and during exposure to DA. Statistical differences between SDs were assessed using an $F$ test or Bartlett's test. ${ }^{* *} p<0.01$. C, Comparison of calcium signals evoked by all odorants $(n=3)$ before and during exposure to DA in each individual $\operatorname{MC}(n=112)$. D, Difference between the distributions of odorant-evoked calcium signals before and during exposure to DA. The distribution under control conditions was subtracted from the distribution obtained in the presence of $D A$, and the difference was normalized to the integrated absolute difference. Positive and negative values indicate that responses of a given amplitude were more frequently and less frequently observed in the presence of DA, respectively. $E$, Cumulative distributions of odorant-evoked calcium signals before and during exposure to DA.F, Correlations between activity patterns across the $112 \mathrm{MCs}$. Left, Color-coded correlation matrix. Right, Mean correlations ( \pm SD) between activity patterns evoked by the same odorants before and during exposure to DA (left), and between activity patterns evoked by different odorants under different conditions (right).

The mean response measured by multiphoton calcium imaging to all odorants increased slightly, but not significantly, in the presence of DA (control, 7.1\% $\Delta F / F$; $\mathrm{DA}, 9.1 \% \Delta F / F ; p=0.1)$. The SD, in contrast, increased significantly (control, $16.1 \% \Delta F / F ; \mathrm{DA}, 18.9 \% \Delta F / F ; p<0.01, F$ test or Bartlett's test; Fig. $8 \mathrm{~B}$ ). Analyses of response amplitude distributions showed that small positive and small negative responses were less frequently observed in the presence of DA, whereas response amplitudes near zero and large positive responses occurred more frequently (Fig. 8C-E). The similarity (Pearson correlation) between responses of all cells to all odorants before and during exposure to DA was high $(r=0.82$; correlation between responses before exposure to DA and after washout: $r=0.86$ ). When calculated individually for each odorant, the mean correlation between activity patterns before and during exposure to DA was $r=0.82 \pm 0.03$ (mean $\pm \mathrm{SD}$; Fig. $8 F$ ). Hence, effects of DA measured by multiphoton calcium imaging were consistent with electrophysiological results and confirm that DA increased the rms contrast of mitral cell activity patterns.

Correlations between MC activity patterns evoked by different odorants were, on average, not decreased in the presence of DA (Fig. 8F). Similar results were obtained when calcium signals were temporally deconvolved to reconstruct the underlying firing rate changes (data not shown) (Yaksi and Friedrich, 2006). The increased rms contrast in the presence of DA did therefore not reduce the overlap of activity patterns representing similar stimuli.

\section{Optogenetic analysis of DA release}

To examine the mode and kinetics of dopaminergic transmission, we optically stimulated DA-INs using a transgenic fish line expressing channelrhodopsin-2 fused to YFP (Chr2YFP) (Nagel et al., 2003; Boyden et al., 2005) under the control of dlx4/6 promoter/enhancer elements and the Tet system [Dlx4/6:itTA/Ptet:Chr2YFP Line 01 (Zhu et al., 2009)]. Expression of Chr2YFP in this line recapitulates the expression of GFP in the OB of a dlx4/6:GFP transgenic line described previously (Zerucha et al., 2000; Zhu et al., 2009). In the adult OB, the dlx4/6 promoter/enhancer elements drive expression in periglomerular and/or shortaxon cells, which are likely to include DAINs (Zhu et al., 2009). We verified this assumption by immunocytochemistry and found that 14\% of GFP-positive neurons coexpressed TH $(n=799$ GFP-positive cells), and $53 \%$ of TH-positive neurons also expressed GFP ( $n=218$ TH-positive cells; 
A

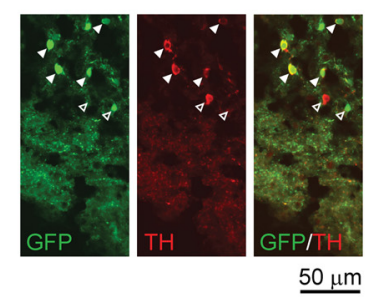

C

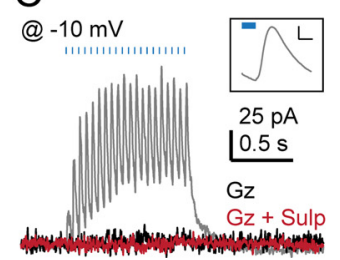

B

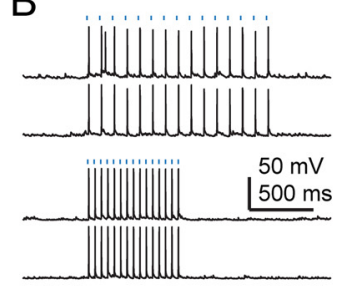

$\mathrm{D}$

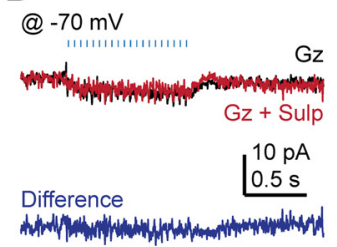

E
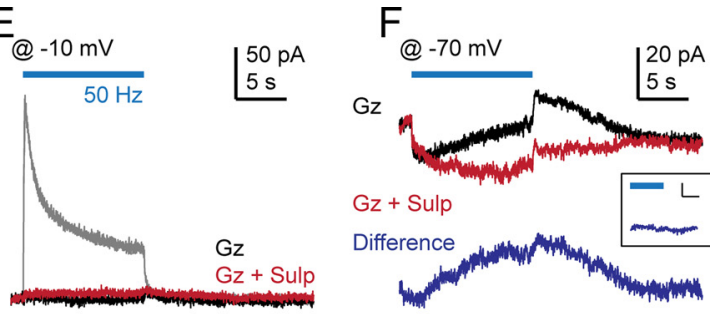

G

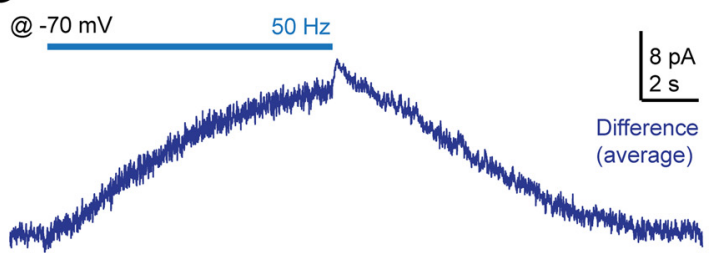

Figure 9. Optogenetic stimulation of interneurons. $\boldsymbol{A}$, Left, Expression of GFP and TH in dlx:GFP transgenic fish. $\boldsymbol{B}$, Responses of a Chr2YFP-positive neuron in a dlx4/6:itTA/Ptet:Chr2YFP transgenic fish to trains of blue light pulses (10 and $20 \mathrm{~Hz} ; 3 \mathrm{~ms}$ pulse duration; 2 repetitions each). C, Currents evoked in a MC at $-10 \mathrm{mV}$ by optical stimulation ( $20 \mathrm{~Hz}, 1 \mathrm{~s}$ ) in a dlx4/6:itTA/Ptet:Chr2YFP transgenic fish in the presence of NBQX and APV. Gray, Control; Gz, Gabazine plus CGP 54626; Sulp, sulpiride. Inset, Pulse-triggered current average (control). Calibration: 20 pA, $20 \mathrm{~ms}$. D, Currents evoked at $-70 \mathrm{mV}$ and their difference (Gz $-[\mathrm{Gz}+$ Sulp]). $\boldsymbol{E}, \boldsymbol{F}$, Same as in $\boldsymbol{C}$ and $\boldsymbol{D}$ but stimulation was longer and more intense ( $50 \mathrm{~Hz}, 10 \mathrm{~s}$ ). Difference (blue) shows sulpiride-sensitive current (Gz - [Gz + Sulp]). Inset, Pulse-triggered average of difference current. Calibration: 1 pA, 5 ms. G, Difference current averaged over 9 MCs (MCs with a nonstable fast inward current were excluded).

Fig. 9A). Hence, dlx4/6 promoter/enhancer elements drive expression in a subset of DA-INs in adult zebrafish.

Using the Dlx4/6:itTA/Ptet:Chr2YFP transgenic line, we optically stimulated interneurons by trains of blue light pulses (3-10 ms duration). Whole-cell recordings from Chr2YFP-positive neurons showed that optical stimulation reliably evoked action potential firing (Fig. 9B; similar results were obtained in six of six neurons). We then applied trains of blue light pulses (10 ms pulse duration) and recorded synaptic currents in MCs in the presence of NBQX $(5 \mu \mathrm{M})$ and APV $(50 \mu \mathrm{M})$. At a holding potential near the reversal potential of glutamatergic synaptic currents $(-10$ $\mathrm{mV}$ ), optical stimulation evoked outward currents (Fig. 9C,E; gray) that were time-locked to the optical stimulus (pulsetriggered average; Fig. 9C, inset). These currents were completely blocked by Gabazine and CGP 54626 (Fig. 9C,E; black), directly demonstrating that optical stimulation triggers fast GABA release from periglomerular/short-axon cells.

At a holding potential of $-70 \mathrm{mV}$, optical stimulation often evoked a small inward current of unknown origin that was insensitive to Gabazine/CGP 54626 and sulpiride (Fig. 9D). In addition, long pulse trains $(50 \mathrm{~Hz}, 10 \mathrm{~s})$ also activated a slow outward (hyperpolarizing) current that was blocked by sulpiride $(n=16$ MCs; Fig. $9 F, G$ ). Time constants of exponential fits to the mean difference current (control - sulpiride; Fig. 9G) were 10.7 s for the rising phase and $4.7 \mathrm{~s}$ for the falling phase after stimulus offset. The mean amplitude of the difference current after $10 \mathrm{~s}$ was $16.1 \pm 7.7 \mathrm{pA}$. Unlike GABAergic currents, the sulpiridesensitive current was not time-locked to the stimulus pulses (Fig. $9 F$, inset). DA is therefore released from interneurons by electrical activity and hyperpolarizes MCs by acting on $\mathrm{D}_{2}$-like receptors. Contrary to GABAergic inhibition, however, the $\mathrm{D}_{2}$ receptordependent effect of DA was much slower, asynchronous, and mediated by different conductances.

\section{Discussion}

Although DA-INs in the OB are one of the largest and most conserved populations of DA neurons, the role of DA in olfaction is still unclear. We found no effect of DA on synaptic input from sensory afferents to MCs in zebrafish, possibly because $\mathrm{D}_{2}$-like receptors are not expressed on afferent axons, as found in frogs (Duchamp-Viret et al., 1997). Presynaptic dopaminergic modulation of sensory input to the $\mathrm{OB}$ therefore differs between vertebrate species, unlike GABAergic presynaptic inhibition via $\mathrm{GABA}_{\mathrm{B}}$ receptors (Wachowiak and Cohen, 1999; AroniadouAnderjaska et al., 2000; McGann et al., 2005; Tabor et al., 2008).

DA hyperpolarized MCs, decreased their input resistance, and reduced spontaneous firing. These effects were observed also in the presence of synaptic blockers, suggesting that DA modulates intrinsic conductances in MCs. To complement pharmacological experiments, we also stimulated periglomerular/short-axon cells expressing Chr2YFP by light. This method has obvious limitations because Chr2YFP was expressed only in a subset of DA neurons $(\sim 50 \%)$, because effects mediated by other neurons and neurotransmitters had to be blocked pharmacologically, and because it is unknown whether the optical stimulation patterns reflect natural activity patterns of DA-INs. Nevertheless, optical stimulation of DA-INs enabled us to analyze effects of DA release triggered by neuronal activity. This approach revealed a slow dopaminergic outward current in MCs and a faster inward current of unknown origin.

Most of the observed effects of DA were blocked by an antagonist of $\mathrm{D}_{2}$-like receptors. However, the $\mathrm{D}_{2}$ antagonist did not completely reverse the effect of DA on input resistance of MCs, and it did not affect the fast inward current evoked by optical stimulation. Recent results show that DA activates inward and outward currents in external tufted cells via $\mathrm{D}_{1}$ - and $\mathrm{D}_{2}$-like receptors, respectively (Liu et al., 2011), suggesting that $\mathrm{D}_{2}$-independent effects of DA may, at least in part, be mediated by $\mathrm{D}_{1}$-like receptors. These results further raise the possibility that DA-INs mediate both excitatory and inhibitory interactions between principal neurons via different mechanisms. In addition, DA may modulate interneurons or synapses that we have not specifically investigated (Brünig et al., 1999; Davila et al., 2003). Future studies focusing on $D_{1}$-like receptors are therefore likely to reveal additional effects of DA. 
The main effect of DA on input-output functions of MCs was a membrane potential shift away from spike threshold. In addition, DA slightly increased the response gain. Consistent with these antagonistic effects on responses to current injection, DA reduced weak, but enhanced strong, responses to odorants, resulting in a significant increase in the SD of population activity patterns. DA therefore increased the rms contrast of odorantevoked activity patterns across MCs with little or no effect on the mean response intensity.

It has been proposed that contrast enhancement reduces the overlap (correlation) between MC activity patterns evoked by similar odorants and thereby enhances their discriminability (Yokoi et al., 1995; Cleland and Sethupathy, 2006; Arevian et al., 2008). However, we found no decrease in correlations between MC activity patterns in the presence of DA. Obviously, contrast enhancement results in pattern decorrelation only when patterns overlap predominantly in the weakly active elements that become suppressed. In the $\mathrm{OB}$, however, a substantial contribution to high pattern correlations comes from clusters of strongly active MCs (Yaksi et al., 2007). These results emphasize that contrast enhancement and decorrelation are different computations that may occur independently. Decorrelation can facilitate the discrimination of odor-encoding activity patterns and their storage by autoassociative networks because patterns can be more easily separated by a simple classifier. The possible computational function of contrast enhancement, however, remains unclear. It is also not known whether DA mediates a global enhancement of rms contrast under physiological conditions because the pattern of DA release may differ from the spatially uniform DA application in our pharmacological experiments. Further studies are therefore required to assess the effect of DA on the contrast of odorant-evoked activity patterns and its potential role in odor processing.

To understand the function of DA in the $\mathrm{OB}$, it is critical to clarify how DA is released and transmitted to its targets. In brain slices, electrical stimulation of sensory afferents evoked DAmediated currents in interneurons only in the presence of a DA transport inhibitor. It has therefore been suggested that dopaminergic effects in the $\mathrm{OB}$ require pronounced or prolonged changes in neural activity (Maher and Westbrook, 2008). Consistent with this hypothesis, direct optical stimulation of periglomerular/short-axon cells produced a $\mathrm{D}_{2}$-dependent current in MCs only in response to extended trains of stimuli. This hyperpolarizing current was slow and not time-locked to the stimulus, suggesting that $\mathrm{DA}$ acting on $\mathrm{D}_{2}$-like receptors is released asynchronously and/or transmitted by volume transmission, as in other brain areas. Hence, GABA and DA are both released from DA-INs by electrical activity and inhibit MCs, but on different timescales. These results suggest that GABAergic transmission is involved in dynamic odor processing, whereas the slow $\mathrm{D}_{2}$-dependent actions of DA are unlikely to influence fast odorant responses. $\mathrm{D}_{2}$-dependent effects of DA may therefore modulate odorant responses on slower timescales and adapt odor processing to changes in the environment. DA-INs receiving direct sensory input (K. Kosaka and T. Kosaka, 2005; Kiyokage et al., 2010) are strategically located to generate a modulatory output signal by integration of slowly changing inputs. DA could therefore mediate similar general functions in the $\mathrm{OB}$ and the retina, although the mechanisms of sensory processing and their modulation by DA are most likely different.

The additive membrane potential shift caused by DA is fundamentally different from multiplicative gain modulation in other parts of the nervous system. Gain modulation adjusts, for example, the sensitivity of sensory neurons to the relevant range of stimulus intensities. An additive modulation, in contrast, shifts the threshold-rather than the sensitivity - of neuronal responses. Such an operation could offset slowly changing or fluctuating background input while maintaining sensitivity to other inputs. One possible function of DA may therefore be an "additive adaptation" that filters out slow variations in background odors without compromising sensitivity to other stimuli. To test this hypothesis, it will be important to determine whether effects of DA are restricted to specific glomeruli. Moreover, slow shifts in membrane potential can adapt sensory responses to higher moments of stimulus distributions such as their variance (Arganda et al., 2007). The adaptation to more complex features of stimulus distributions has not been studied intensely in olfaction but is important in other sensory systems, for example to optimize contrast and motion sensitivity in vision (Blakemore and Campbell, 1969; Meister and Berry, 1999; Brenner et al., 2000).

\section{References}

Adam Y, Mizrahi A (2011) Long-term imaging reveals dynamic changes in the neuronal composition of the glomerular layer. J Neurosci 31:7967-7973.

Arevian AC, Kapoor V, Urban NN (2008) Activity-dependent gating of lateral inhibition in the mouse olfactory bulb. Nat Neurosci 11:80-87.

Arganda S, Guantes R, de Polavieja GG (2007) Sodium pumps adapt spike bursting to stimulus statistics. Nat Neurosci 10:1467-1473.

Aroniadou-Anderjaska V, Zhou FM, Priest CA, Ennis M, Shipley MT (2000) Tonic and synaptically evoked presynaptic inhibition of sensory input to the rat olfactory bulb via $\mathrm{GABA}_{\mathrm{B}}$ heteroreceptors. J Neurophysiol 84:1194-1203.

Baker H (1990) Unilateral, neonatal olfactory deprivation alters tyrosine hydroxylase expression but not aromatic amino acid decarboxylase or GABA immunoreactivity. Neuroscience 36:761-771.

Berkowicz DA, Trombley PQ (2000) Dopaminergic modulation at the olfactory nerve synapse. Brain Res 855:90-99.

Björklund A, Dunnett SB (2007) Dopamine neuron systems in the brain: an update. Trends Neurosci 30:194-202.

Blakemore C, Campbell FW (1969) On the existence of neurones in the human visual system selectively sensitive to the orientation and size of retinal images. J Physiol 203:237-260.

Blumhagen F, Zhu P, Shum J, Schärer YP, Yaksi E, Deisseroth K, Friedrich RW (2011) Neuronal filtering of multiplexed odour representations. Nature 479:493-498.

Boyden ES, Zhang F, Bamberg E, Nagel G, Deisseroth K (2005) Millisecondtimescale, genetically targeted optical control of neural activity. Nat Neurosci 8:1263-1268.

Brenner N, Bialek W, de Ruyter van Steveninck R (2000) Adaptive rescaling maximizes information transmission. Neuron 26:695-702.

Brünig I, Sommer M, Hatt H, Bormann J (1999) Dopamine receptor subtypes modulate olfactory bulb gamma-aminobutyric acid type A receptors. Proc Natl Acad Sci U S A 96:2456-2460.

Byrd CA, Brunjes PC (1995) Organization of the olfactory system in the adult zebrafish: histological, immunohistochemical, and quantitative analysis. J Comp Neurol 358:247-259.

Chance FS, Abbott LF, Reyes AD (2002) Gain modulation from background synaptic input. Neuron 35:773-782.

Cleland TA, Sethupathy P (2006) Non-topographical contrast enhancement in the olfactory bulb. BMC Neurosci 7:7.

Coronas V, Srivastava LK, Liang JJ, Jourdan F, Moyse E (1997) Identification and localization of dopamine receptor subtypes in rat olfactory mucosa and bulb: a combined in situ hybridization and ligand binding radioautographic approach. J Chem Neuroanat 12:243-257.

Davila NG, Blakemore LJ, Trombley PQ (2003) Dopamine modulates synaptic transmission between rat olfactory bulb neurons in culture. J Neurophysiol 90:395-404.

Duchamp-Viret P, Coronas V, Delaleu JC, Moyse E, Duchamp A (1997) Dopaminergic modulation of mitral cell activity in the frog olfactory bulb: a combined radioligand binding-electrophysiological study. Neuroscience 79:203-216.

Ennis M, Zhou FM, Ciombor KJ, Aroniadou-Anderjaska V, Hayar A, Borrelli 
E, Zimmer LA, Margolis F, Shipley MT (2001) Dopamine $\mathrm{D}_{2}$ receptormediated presynaptic inhibition of olfactory nerve terminals. J Neurophysiol 86:2986-2997.

Euler T, Hausselt SE, Margolis DJ, Breuninger T, Castell X, Detwiler PB, Denk W (2009) Eyecup scope-optical recordings of light stimulus-evoked fluorescence signals in the retina. Pflugers Arch 457:1393-1414.

Friedrich RW, Korsching SI (1997) Combinatorial and chemotopic odorant coding in the zebrafish olfactory bulb visualized by optical imaging. Neuron 18:737-752.

Friedrich RW, Laurent G (2001) Dynamic optimization of odor representations in the olfactory bulb by slow temporal patterning of mitral cell activity. Science 291:889-894.

Friedrich RW, Habermann CJ, Laurent G (2004) Multiplexing using synchrony in the zebrafish olfactory bulb. Nat Neurosci 7:862-871.

Friedrich RW, Mack-Bucher JA, Li J (2006) Opto- and electrophysiological approaches in the central nervous system of zebrafish. In: Using zebrafish to study neuroscience (Nicolson T, ed), pp 33-42. Atlanta, GA: Society for Neuroscience.

Gall CM, Hendry SH, Seroogy KB, Jones EG, Haycock JW (1987) Evidence for coexistence of GABA and dopamine in neurons of the rat olfactory bulb. J Comp Neurol 266:307-318.

Gutièrrez-Mecinas M, Crespo C, Blasco-Ibáñez JM, Gracia-Llanes FJ, Marqués-Marí AI, Nácher J, Varea E, Martínez-Guijarro FJ (2005) Distribution of $\mathrm{D}_{2}$ dopamine receptor in the olfactory glomeruli of the rat olfactory bulb. Eur J Neurosci 22:1357-1367.

Hack MA, Saghatelyan A, de Chevigny A, Pfeifer A, Ashery-Padan R, Lledo PM, Götz M (2005) Neuronal fate determinants of adult olfactory bulb neurogenesis. Nat Neurosci 8:865-872.

Higashijima S, Masino MA, Mandel G, Fetcho JR (2003) Imaging neuronal activity during zebrafish behavior with a genetically encoded calcium indicator. J Neurophysiol 90:3986-3997.

Holt GR, Koch C (1997) Shunting inhibition does not have a divisive effect on firing rates. Neural Comput 9:1001-1013.

Hsia AY, Vincent JD, Lledo PM (1999) Dopamine depresses synaptic inputs into the olfactory bulb. J Neurophysiol 82:1082-1085.

Kiyokage E, Pan YZ, Shao Z, Kobayashi K, Szabo G, Yanagawa Y, Obata K, Okano H, Toida K, Puche AC, Shipley MT (2010) Molecular identity of periglomerular and short axon cells. J Neurosci 30:1185-1196.

Kosaka K, Kosaka T (2005) Synaptic organization of the glomerulus in the main olfactory bulb: compartments of the glomerulus and heterogeneity of the periglomerular cells. Anat Sci Int 80:80-90.

Kosaka T, Kosaka K (2011) "Interneurons" in the olfactory bulb revisited. Neurosci Res 69:93-99.

Li J, Mack JA, Souren M, Yaksi E, Higashijima S, Mione M, Fetcho JR, Friedrich RW (2005) Early development of functional spatial maps in the zebrafish olfactory bulb. J Neurosci 25:5784-5795.

Liu S, Shao Z, Puche A, Shipley MT (2011) Dopamine-GABAergic cotransmission from short-axon to external tufted cells activates an inhibitoryexcitatory switch. Soc Neurosci Abstr 37:475.26.

Maher BJ, Westbrook GL (2008) Co-transmission of dopamine and GABA in periglomerular cells. J Neurophysiol 99:1559-1564.

Mathieson WB, Maler L (1988) Morphological and electrophysiological properties of a novel in vitro preparation: the electrosensory lateral line lobe brain slice. J Comp Physiol A 163:489-506.

McGann JP, Pírez N, Gainey MA, Muratore C, Elias AS, Wachowiak M (2005) Odorant representations are modulated by intra- but not interglomerular presynaptic inhibition of olfactory sensory neurons. Neuron 48:1039-1053.

Meister M, Berry MJ 2nd (1999) The neural code of the retina. Neuron 22:435-450.

Nagel G, Szellas T, Huhn W, Kateriya S, Adeishvili N, Berthold P, Ollig D, Hegemann P, Bamberg E (2003) Channelrhodopsin-2, a directly lightgated cation-selective membrane channel. Proc Natl Acad Sci U S A 100:13940-13945.
Nickell WT, Norman AB, Wyatt LM, Shipley MT (1991) Olfactory bulb DA receptors may be located on terminals of the olfactory nerve. Neuroreport 2:9-12.

Niessing J, Friedrich RW (2010) Olfactory pattern classification by discrete neuronal network states. Nature 465:47-52.

Panzanelli P, Fritschy JM, Yanagawa Y, Obata K, Sassoè-Pognetto M (2007) GABAergic phenotype of periglomerular cells in the rodent olfactory bulb. J Comp Neurol 502:990-1002.

Park HC, Kim CH, Bae YK, Yeo SY, Kim SH, Hong SK, Shin J, Yoo KW, Hibi M, Hirano T, Miki N, Chitnis AB, Huh TL (2000) Analysis of upstream elements in the $\mathrm{HuC}$ promoter leads to the establishment of transgenic zebrafish with fluorescent neurons. Dev Biol 227:279-293.

Parrish-Aungst S, Shipley MT, Erdelyi F, Szabo G, Puche AC (2007) Quantitative analysis of neuronal diversity in the mouse olfactory bulb. J Comp Neurol 501:825-836.

Parrish-Aungst S, Kiyokage E, Szabo G, Yanagawa Y, Shipley MT, Puche AC (2011) Sensory experience selectively regulates transmitter synthesis enzymes in interglomerular circuits. Brain Res 1382:70-76.

Peli E (1990) Contrast in complex images. J Opt Soc Am A 7:2032-2040.

Pologruto TA, Sabatini BL, Svoboda K (2003) ScanImage: flexible software for operating laser scanning microscopes. BioMed Eng OnLine 2:13.

Rothman JS, Cathala L, Steuber V, Silver RA (2009) Synaptic depression enables neuronal gain control. Nature 457:1015-1018.

Suter BA, O'Connor T, Iyer V, Petreanu LT, Hooks BM, Kiritani T, Svoboda K, Shepherd GM (2010) Ephus: multipurpose data acquisition software for neuroscience experiments. Front Neural Circuits 4:100.

Tabor R, Friedrich RW (2008) Pharmacological analysis of ionotropic glutamate receptor function in neuronal circuits of the zebrafish olfactory bulb. PLoS One 3:e1416.

Tabor R, Yaksi E, Friedrich RW (2008) Multiple functions of $\mathrm{GABA}_{\mathrm{A}}$ and $\mathrm{GABA}_{\mathrm{B}}$ receptors during pattern processing in the zebrafish olfactory bulb. Eur J Neurosci 28:117-127.

Wachowiak M, Cohen LB (1999) Presynaptic inhibition of primary olfactory afferents mediated by different mechanisms in lobster and turtle. J Neurosci 19:8808-8817.

Weber F, Machens CK, Borst A (2010) Spatiotemporal response properties of optic-flow processing neurons. Neuron 67:629-642.

Wiechert MT, Judkewitz B, Riecke H, Friedrich RW (2010) Mechanisms of pattern decorrelation by recurrent neuronal circuits. Nat Neurosci 13:1003-1010.

Witkovsky P (2004) Dopamine and retinal function. Doc Ophthalmol 108:17-40.

Wullimann MF, Mueller T (2004) Teleostean and mammalian forebrains contrasted: evidence from genes to behavior. J Comp Neurol 475:143-162.

Yaksi E, Friedrich RW (2006) Reconstruction of firing rate changes across neuronal populations by temporally deconvolved $\mathrm{Ca}^{2+}$ imaging. Nat Methods 3:377-383.

Yaksi E, Judkewitz B, Friedrich RW (2007) Topological reorganization of odor representations in the olfactory bulb. PLoS Biol 5:e178.

Yokoi M, Mori K, Nakanishi S (1995) Refinement of odor molecule tuning by dendrodendritic synaptic inhibition in the olfactory bulb. Proc Natl Acad Sci U S A 92:3371-3375.

Zerucha T, Stühmer T, Hatch G, Park BK, Long Q, Yu G, Gambarotta A, Schultz JR, Rubenstein JL, Ekker M (2000) A highly conserved enhancer in the Dlx5/Dlx6 intergenic region is the site of crossregulatory interactions between Dlx genes in the embryonic forebrain. J Neurosci 20:709-721.

Zhu P, Narita Y, Bundschuh ST, Fajardo O, Schärer YP, Chattopadhyaya B, Bouldoires EA, Stepien AE, Deisseroth K, Arber S, Sprengel R, Rijli FM, Friedrich RW (2009) Optogenetic dissection of neuronal circuits in zebrafish using viral gene transfer and the Tet system. Front Neural Circuits $3: 21$. 